\title{
New Possible Astronomic Alignments at the Megalithic Site of Göbekli Tepe, Turkey
}

\author{
Alessandro De Lorenzis, Vincenzo Orofino* \\ Dipartimento di Matematica e Fisica "E. De Giorgi”, Università del Salento, Lecce, Italy \\ Email: ale7delo@hotmail.it,
}

Received 3 January 2015; accepted 22 January 2015; published 26 January 2015

Copyright (C) 2015 by authors and Scientific Research Publishing Inc.

This work is licensed under the Creative Commons Attribution International License (CC BY).

http://creativecommons.org/licenses/by/4.0/

(c) () Open Access

\section{Abstract}

Göbekli Tepe is the oldest and one of the most important among the megalithic sites in the world. Its archaeoastronomical relevance has been recently evidenced by Collins (2013), according to whom the central pillars in four of the enclosures discovered in the site are oriented toward the setting point of the star Deneb ( $\alpha \mathrm{Cyg}$ ), as this point moves in the course of the time, due to the equinox precession and the proper motion of the star. Taking into account these effects, Collins (2013) obtained an astronomical dating for the various enclosures which agrees rather well with the one obtained by Dietrich (2011) with the technique of carbon-14. In the present paper the careful evaluation of the effects caused by atmospheric extinction has enabled us to verify that the central pillars of the studied enclosures are in fact turned to face the setting point of Deneb, but these alignments occurred in epochs, still in agreement with the ones obtained by Dietrich (2011), but different from those proposed by Collins (2013). We have also individuated, for the first time, the probable astronomic alignments of two other enclosures at Göbekli Tepe, i.e. enclosures $F$ and A. In particular, the first one seems to be oriented towards the rising point of the Sun on the day of the Harvest Festival, a day approximately halfway between the summer solstice and the autumn equinox. The second one, instead, shows an orientation towards the rising point of the Moon at its minor standstill. The positions of both celestial bodies have been obtained by extrapolating their declination to the date of the presumed construction reported by Dietrich (2011). A short discussion about the putative cultural motivations of these alignments is also presented.

\section{Keywords}

Megalithic Temples, Archaeoastronomy, Astronomic Alignments, Harvest Festival, Lunar Standstill

\section{Introduction}

A conspicuous part of archaeoastronomical research is aimed at individuating the possible alignments that some

${ }^{*}$ Corresponding author. 
megalithic complexes, built all over the world by ancient civilizations, might present with regard to the position occupied in the sky by some celestial objects. There are numerous instances of sets of stones, or single structures, oriented towards the point where the Sun (Calledda \& Proverbio, 2004; Magli, 2009), the Moon (Ruggles, 1985; Ruggles \& Burl, 1985; Magli, 2009), or bright stars or clusters of stars (North, 1996; Calledda \& Proverbio, 2004; Zedda \& Belmonte, 2004; Belmonte, Shaltout, \& Fekri, 2008; Magli, 2009), rose or set in particular days, often related to religious festivals or agricultural events. And this applies also to the oldest megalithic site in the world, Göbekli Tepe, that stands on the summit of a hill of $780 \mathrm{~m}$ in height, at about $13 \mathrm{~km}$ north-east of the city of Şanlıurfa, Turkey. Probably built during the second half of the tenth millennium BC, during the PPNA (PrePottery Neolithic A, 9800-8700 BC-Dietrich, 2011) period, the monumental complex dates back to 7000 years before Stonehenge and the great Egyptian pyramids of Giza.

The archaeological site of Göbekli Tepe is made up of a series of rings or enclosures (about 20, of which 16 underground and 4 excavated). The first enclosures to be found were assigned the letters A, B, C and D according to the order of their discovery. Later more enclosures were found and indicated with successive letters of the alphabet: of particular interest are the E, F and G enclosures, although they do not boast the same monumental character of the first four (Schmidt, 2010). The main feature they have in common is the presence at the centre of each of two enormous, T-shaped monolithic limestone pillars, of a height of between 3 and 6 meters, surrounded by other pillars of the same shape but not as tall as the central ones, set out around the enclosure wall. Enclosures E and F only have the couple of central pillars.

The T-shaped pillars have been worked on with meticulous care by the site's creators, if we are to go by the presence of numerous, well delineated figures carved into these structures: abstract symbols, but also numerous animals (foxes, lions, oxen, hyenas, scorpions, spiders, various reptiles, insects and birds, especially vultures). Figure 1 illustrates a reconstruction of the plan of the site.

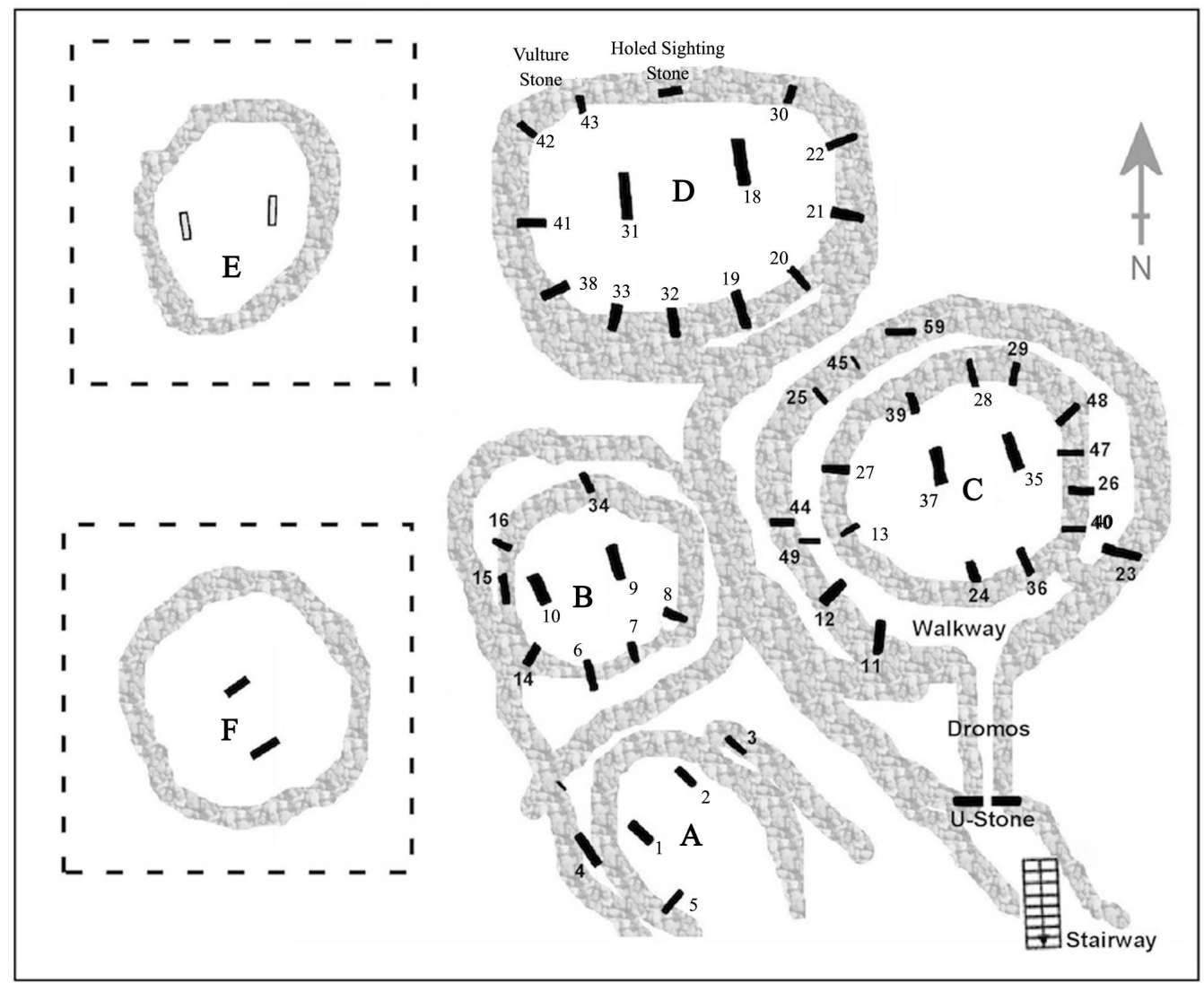

Figure 1. Plan of Göbekli Tepe. Enclosures A, B, C and D are in the context, with enclosure E shown as a "satellite" because of the fact that it is situated outside, towards the west, with respect to the main group of structures, known as "The Rock Temple”. Enclosure F is also outside the main group. In the map, the steps discovered in 2012, to gain access to the site, are also shown (Source: Hale \& Collins, 2013). 


\section{Archaeoastronomical Implications}

What exactly were the enclosures of Göbekli Tepe plain for? And above all, were the T-shaped pillars aligned towards a particular object in the sky? It has been suggested that the pillars pointed in the direction of Sirius (Magli, 2013) or towards the constellations of Taurus or Orion and the clusters of the Pleiades (Schoch, 2012). But these, like other interpretations, have been questioned by Collins (2013). It can be said with certainty that the main candidate presenting orientations towards celestial bodies is the pair of central pillars present in each of these structures. These pillars might be a sort of astronomical marker (Collins, 2013) since, at the time of their construction it was possible to enjoy, from every enclosure, a view of the horizon without any artificial obstacles, apart from the natural ones (mountains), free, therefore, in every direction, thanks to the height of the site (780 m a.s.l.).

\section{Checking the Alignments towards Deneb ( $\alpha$ Cygni) of Enclosures D, C, E and B}

Collins (2013) has noticed that the central pillars in enclosures D, E, C and B are all oriented just west of north, and, equally, just east of south (see Table 1). The author does not give any details about how the surveying was carried out, so the azimuth bearings supplied must be considered to be affected by uncertainty of the order of at least one degree. Of all the stars that populate the Northern skies (the only zone compatible with the orientation of the pillars-Collins, 2013), the best candidate as the target of the central pillars, as chosen by the builders of Göbekli Tepe was probably Deneb ( $\alpha$ Cyg), the brightest star of the constellation of Cygnus, the Celestial Bird, or Northern Cross. The movements of this star might well have struck these ancient populations because of its rapid setting/rising cycle, i.e., its brief time interval (lasting a few hours in the same night) that passed between the setting and the successive rising of the star, at the epoch when the enclosures were built. In fact, this particular behaviour of Deneb, almost like a circumpolar star, probably reminded the builders of the site of the cycle of birth/death/rebirth that characterizes human life (Collins, 2013). Taking into consideration the effects of the proper motion and the precession of the equinoxes on the position of Deneb in the course of the time, Collins (2013) has proposed the dating presented in Table 1 for the various enclosures. He has based his calculations on a value of the angle of extinction of Deneb fixed at 2 degrees, including the corrections for the refraction by means of the Stellarium astronomical software.

These orientations and the relative dating proposed by Collins (2013) have been verified in this work by means of the application of a new archaeoastronomical procedure. The study is based mainly on a careful evaluation of the effects that atmospheric extinction has on the coordinates of a star, a factor which is often neglected in many works of archaeoastronomical subject, thus leading to results which are often completely misleading (for a discussion of this subject, see Schaefer, 1993).

The phenomenon of atmospheric extinction plays a crucial role in the determination of the rising of a star; in fact, a star becomes visible only when its height above the local astronomical horizon has already reached a consistent value, known as height of prime visibility (HPV). Analogue considerations obviously hold for the setting. The procedure we have followed to determine the new dating can be summarized into 5 basic steps (for the details, see De Lorenzis, 2013):

1) calculation of the extinction coefficient by means of the use of data regarding humidity in the observation site;

Table 1. Data relative to the four enclosures oriented towards Deneb. In the first column we find the name of the enclosure; in the second column the orientation azimuth of the central pillars according to Collins (2013); in the third the date of the presumed construction of the enclosures proposed by Collins (2013); in the fourth the dating proposed by us; in the fifth the difference $(\Delta)$ between the two previous datings; in the sixth the HPV used in our research, as found by CDC; in the seventh the rising azimuth of the star, also found by CDC.

\begin{tabular}{ccccccc}
\hline Enclosure & Azimuth $\left(^{\circ}\right)$ & Year Collins (BC) & Year CDC (BC) & $\Delta$ (Years) & HPV CDC $\left(^{\circ}\right)$ & AZ Rising CDC $\left(^{\circ}\right)$ \\
\hline D & 353 & 9400 & 9590 & 190 & 1.65 & 7.02 \\
E & 350 & 9290 & 9463 & 173 & 1.65 & 9.99 \\
C & 345 & 8980 & 9156 & 176 & 1.67 & 14.99 \\
B & 337 & 8245 & 8409 & 164 & 1.72 & 23.00 \\
\hline
\end{tabular}


2) calculation of the air mass passed through by the starlight and its extinction caused by the Earth's atmosphere;

3) determination of the HPV of Deneb by means of the use of Bouguer's law of attenuation;

4) checking of the possible presence of reliefs in the directions where the enclosures are oriented;

5) search for the date when the calculated value of HPV of Deneb is observed.

The last point has been addressed by means of the Cartes du Ciel (CDC) software (downloadable at

http://www.ap-i.net/skychart/it/start), which, unlike Stellarium, rightly takes into consideration the effects of the precession of the equinoxes and the stars' proper motions on the celestial coordinates even in very remote epochs. The new dating obtained by this method is reported in Table 1 .

If we attribute an error $\Delta(\mathrm{AZ})= \pm 1^{\circ}$ to the azimuth measurements reported by Collins (2013), we are able to define the period (obtained again by means of CDC software), in which it was possible to see Deneb set at an azimuth that fell within the angular interval considered. This period is reported in Table 2 where it is compared with the dating obtained by Dietrich (2011) by means of analysis of carbon-14.

We can therefore affirm that the hypothesis proposed by Collins (2013), according to which the builders of Göbekli Tepe would have wanted to celebrate their beliefs by means of the setting/rising cycle of Deneb as an allegory of the birth/death/rebirth cycle of human life, seems as plausible as the dating. The differences (typically about 200 years) between the dating obtained by us and that by Collins (2013) are mainly due to the different ways in which the effects of atmospheric extinction on the measurements of celestial coordinates are taken into account in the two works. In addition, the difference shown in Table 1 is also the fruit of the use by Collins (2013) of an astronomic software (Stellarium) which is not adequate in evaluating the positions of the stars in remote past epochs, as has already been demonstrated (De Lorenzis, 2011).

To complete the description of the site, we have to determine the possible alignments of enclosures $\mathrm{A}$ and $\mathrm{F}$, which we still have very little information about, both as far as regards their orientation and their dating.

\section{The Alignment of Enclosure F towards the Sun}

The only information available on the orientation of enclosure F comes by way of Collins (2013), who indicates a disposition of the central pillars of the enclosure towards east-northeast or towards west-southwest, directions, according to the author, which are very close to that of the Sun rising at the summer solstice or setting at the winter solstice, respectively. Regarding this, Collins (2013) does not supply any numerical data, but, by a simple geometrical calculation, it can be estimated that the azimuth relative to the first possible orientation is equal to about $67^{\circ}-68^{\circ}\left(\mathrm{N} 67.5^{\circ} \mathrm{E}\right)$ and that relative to the second orientation about $247^{\circ}-248^{\circ}\left(\mathrm{S} 67.5^{\circ} \mathrm{W}\right)$; both the values can be affected by a minimal uncertainty of a few degrees.

Collins' work also lacks an indication of the possible date of the building of the enclosure. An analysis using the carbon-14 technique carried out by Dietrich (2011) on some bone and apatite samples found in the enclosure supplies an indicative dating going back to circa 8380 BC. Evidently, as Dietrich (2011) himself maintains, this, like the other dating obtained through analysis with carbon-14 for the other enclosures at Göbekli Tepe, is only indicative. In fact, the embryonic state in which the archaeological excavation works carried out at the megalithic site find themselves today, while work is in progress, cannot give this dating a definitive or absolute character and should therefore be considered as preliminary (Dietrich, 2011).

On looking for the day of the year when, in the present epoch, the Sun rises (or sets) at an azimuth of about

Table 2. Comparison between the dating derived for the various enclosures by Dietrich (2011) with the technique of carbon14 and those obtained by us (using CDC) and by Collins (2013). In the third column we see the time interval within which the setting azimuth of Deneb is found within a range of $\pm 1^{\circ}$ from the theoretical value reported in the fourth column of Table 1 .

\begin{tabular}{cccc}
\hline Enclosure & Radiocarbon dating $(\mathrm{BC})$ & CDC dating (BC) & Collins dating (BC) \\
\hline D & {$[9745 ; 9314]$} & {$[9620 ; 9550]$} & 9400 \\
E & {$[9500 ; 8500]$} & {$[9510 ; 9410]$} & 9290 \\
C & {$[9500 ; 8500]$} & {$[9230 ; 9080]$} & 8980 \\
B & {$[8306 ; 8236]$} & {$[8520 ; 8210]$} & 8245 \\
\hline
\end{tabular}


$67^{\circ}$ (or $247^{\circ}$ ), it is possible to find an important date, associated with the Festival of Grain, or the Harvest Festival, a celebration which was particularly relevant for ancient civilizations because it sanctioned the moment of the year's first harvest (Keating, 1861). Today this feast (also known as Lughnasadh) is celebrated on 1st August, that is about 41 days after the summer solstice, and is collocated approximately halfway between the summer solstice and the autumn equinox. On this date, in fact, the rising azimuth of the Sun is equal to $66.5^{\circ}$, which is close to the orientation reported by Collins (2013), i.e. N67.5 ${ }^{\circ}$ E. Very probably (see discussion in Section 6), the builders of Göbekli Tepe had, amongst their main sources of sustenance, apart from hunting, the products of the earth, as indicated by the findings in Layer I of the site reported by Dietrich (2011). So it is likely that they wanted to celebrate this occasion by building one of the enclosures in the direction of the nascent Sun on this particular day of the year.

We may therefore suppose that the central pillars of enclosure $F$ are aligned in the direction of the sunrise on the 41st day after the summer solstice, a day that we conventionally call the day of the Harvest Festival. To evaluate this hypothesis, a procedure, which can be summarized in the following points, was developed (for details, see De Lorenzis, 2013):

1) individuation of the day on which the summer solstice took place in past epochs (by means of the CDC astronomic software), taking into account the effects of the translation of the data due to the precession of the equinoxes;

2) individuation of the day of the Harvest Festival (collocated 41 - 42 days after the summer solstice) in the epochs studied;

3) determination of the azimuth of the rising Sun on the day of the Harvest Festival (obtained by the JPL Horizons routine, see below);

4) reconstruction of the secular trend of the Sun's azimuth on the day of the Harvest Festival;

5) extrapolation of the azimuth datum to the epoch of the building of enclosure $\mathrm{F}$.

The reconstruction of the change over the centuries of the rising azimuth of the Sun on the day of the Harvest Festival has been the result of careful research carried out by means of the generation of ephemerides by means of the Horizons routine supplied by the NASA JPL, available at http://ssd.jpl.nasa.gov/horizons.cgi. To individuate this instant, we have adopted the widespread convention according to which the value of the rising azimuth of the Sun (and the Moon) is the one relative to the moment in which the upper limb of the object goes past the horizon (Horizons User Manual, 2013). The time interval covered by the research ranges from $3000 \mathrm{BC}$ to $2505 \mathrm{AD}$, registering the rising azimuths of the Sun every 275 years starting from 3000 BC. This epoch, in fact, represents the earliest limit for which we can calculate the ephemerides of the Sun (and of the Moon) in all the available astronomical routines. The incomplete nature of the astronomical catalogues for very remote positions in the past and in the future depends on the behaviour of the Earth's orbit. The Earth, in fact, is affected by various gravitational perturbations due to the presence of the other planets of the solar system, distancing itself slightly from the pure Keplerian motion. Although these perturbations are slight, over time they can bring about effects which can be relevant.

As a matter of fact, the declination (and hence the rising azimuth) of the Sun on a given day, which is constant year after year over relatively short time ranges (several centuries), can vary on much longer timescales. In absence of theoretical indications about this long-term secular trend, we have decided to interpolate and then extrapolate the collected data about the rising azimuth of the Sun on the Harvest Festival by using three laws which best fit the data: constant, linear (slightly) decreasing and parabolic. This extrapolation gives an estimate of the rising azimuth at the presumed date of construction of enclosure F (approximated at 8400 BC) in the range $66.2^{\circ}-67.6^{\circ}$, with a most likely value of $67.6^{\circ}$. The latter is obtained with a parabolic trend, which, with its value of the reduced $\chi^{2}$ (Taylor, 1982) equal to 0.07 , gives the best fit of the data.

The values extrapolated in this manner, however, cannot yet be compared with the azimuth of the central pillars supplied by Collins (2013), since we have to take into account another important factor, which is the presence of reliefs in the zone surrounding the megalithic site. By means of Google Earth, it has been established that in the direction previously individuated there is a relief of about $2116 \mathrm{~m}$ that means the field of vision of the horizon surrounding the site is not free anymore. By applying a model of a flat surface, we obtain that the correction to make to the height of the sunrise is equal to $\Delta \mathrm{h}=+0.2^{\circ}$ which, translated in terms of azimuth, corresponds to a variation equal to $\Delta(\mathrm{AZ})=+0.2^{\circ}$. Thus, the estimate for the azimuth of the sunrise at the time of the presumed construction of enclosure $\mathrm{F}$ on the day of the Harvest Festival, corrected for the effect of the topography surrounding the site is somewhere between $66.4^{\circ}$ and $67.8^{\circ}$, with the latter which represents the most likely 
value.

Alternatively, one can assume that the Harvest Festival was celebrated in the past exactly in the midsummer day, that is 46 - 47 days after the summer solstice, corresponding to August 6th of our epoch; in this case, extrapolating and correcting for topography, as described above, the present value of the rising azimuth of the Sun (equal to $68.1^{\circ}$ ), one can obtain a value of the same parameter at approximated $8400 \mathrm{BC}$ in the range $68.0^{\circ}$ $69.4^{\circ}$, with a most likely value of $69.4^{\circ}$. Both results are close (within $2^{\circ}$ ) to the orientation of the central pillars of enclosure $\mathrm{F}\left(\mathrm{N} 67.5^{\circ} \mathrm{E}\right)$.

As already mentioned, Collins (2013) proposes an alignment of the central pillars towards the Sun's rising point on the day of the summer solstice. However, currently, on the day of the summer solstice the rising azimuth of the Sun for a free horizon is equal to about $59.3^{\circ}$. By making the opportune extrapolation (as before), we arrive at an azimuth value at the summer solstice in $8400 \mathrm{BC}$ of between $59.0^{\circ}$ and $60.4^{\circ}$ with a most likely value of $60.4^{\circ}$.

Remembering that the orientation of the central pillars of enclosure $\mathrm{F}$ is quantified as $\mathrm{N} 67.5^{\circ} \mathrm{E}$, it can be affirmed that the possible alignment proposed by Collins (2013) towards the rising point of the Sun on the day of the summer solstice is to be considered unreliable, considering the large difference observed between the values reported above. On the contrary, the values of the rising azimuth of the Sun on the day of the Harvest Festival, found by means of the extrapolation at the epoch of the presumed construction of the enclosure F (and, in particular, the most likely one equal to $67.8^{\circ}$ ), are much closer to the datum relative to the orientation of enclosure. Our alternative hypothesis, although based on an extrapolation, seems more reasonable than that of Collins (2013): it attempts to reconcile the little data known about the dating of the enclosure supplied by Dietrich (2011) with some of the beliefs, connected with the agricultural activity carried out by the builders.

In conclusion, it seems highly plausible that the central pillars of enclosure F at Göbekli Tepe were aligned towards the Sun rising on the day of the Harvest Festival about 8400 BC. This conclusion appears perfectly reasonable, especially on the light of the large uncertainty (of a few degrees) which affects the orientation of the pillars reported by Collins (2013).

\section{The Alignment of Enclosure A towards the Lunar Standtsills}

To complete the picture of the probable alignments of the structural complexes that characterize the Göbekli Tepe plain, enclosure A remains to be analyzed, since in literature there is no information about the possible celestial objectives of the central pillars. They are set almost exactly from north-west towards south-east or viceversa with azimuths equal to $132^{\circ}$ and $312^{\circ}$ (Collins, 2013), and to which it is possible to attribute error to the order of a degree. As far as regards the dating of the enclosure, Collins (2013) speaks of a period of time somewhere between the end of the tenth millennium and the end of the ninth millennium BC. To work with a more precise date, we have assumed as reference date the one proposed by Dietrich (2011) of 8500 BC, based on the study of various finds found inside the enclosure, by means of analysis with carbon-14.

The search for a possible alignment towards a celestial objective is rather difficult with the scarce information at our disposal. Of all the alignments proposed in literature for other megalithic sites, there are numerous ones regarding a presumed orientation towards the stopping points of the Moon, the so-called lunar standstills (Ruggles, 1985; Ruggles \& Burl, 1985; Coffey, 2000; Magli, 2009). The interest that ancient peoples would have regarding the positions occupied in the sky by the Moon when it was in its stopping points is suggested by the consideration that the astronomers of the past would have been able to keep track of the lunar movements, in particular the lunar standstills, by means of simple geometric calculations (Thom, 1971, 1974). For this reason, an analogous orientation has been considered in this work also for the enclosure of Göbekli Tepe. In particular, we have verified the possibility that the central pillars of enclosure A were erected towards the position of the Moon when it was in its extreme lower (minor) standstill. The lunar standstill chosen is in fact the only one, of the four possible ones, whose position is consistent with the orientations of the central pillars of the various enclosures. The technique adopted to find the presumed alignment of enclosure A towards the minor lunar standstill can be summarized in the following steps:

1) collection of data regarding the lunar position over the years by means of the Horizons routine;

2) elaboration of the data by means of a script translated into Interactive Data Language (IDL), for the individuation of the minor lunar standstill in our sample, through the reconstruction of the progress of the Moon during the cycle of retrograde motion of nodes (Metonic cycle), i.e. the passage from one lunar standstill to 
the next of the same kind;

3) reconstruction of the secular trend of the declination of the Moon when it is at the minor lunar standstill;

4) extrapolation of the lunar declination at the epoch of the presumed construction of the enclosure, in order to individuate the rising azimuth on the day in which, at that epoch, the Moon was at the minor lunar standstill.

The aim of the research was to individuate the day on which the lunar standstills took place in the past. To do so, we have found the exact date on which, for the first time, this particular astronomical configuration took place, starting from 3000 BC. In particular we have found that the first minimum for the lunar declination, corresponding to the moment in which our satellite is at its minor lunar standstill, took place on May 12th 2983 BC, when $\delta=-30.0962^{\circ}$. Once this was done, the other years in which this phenomenon occurred were individuated, by taking advantage of the periodicity of the cycle of lunar standstills (equal to about 18.6 years). In this way we have calculated the typical trend of the lunar declination in function of the time, as shown in Figure 2: for seek

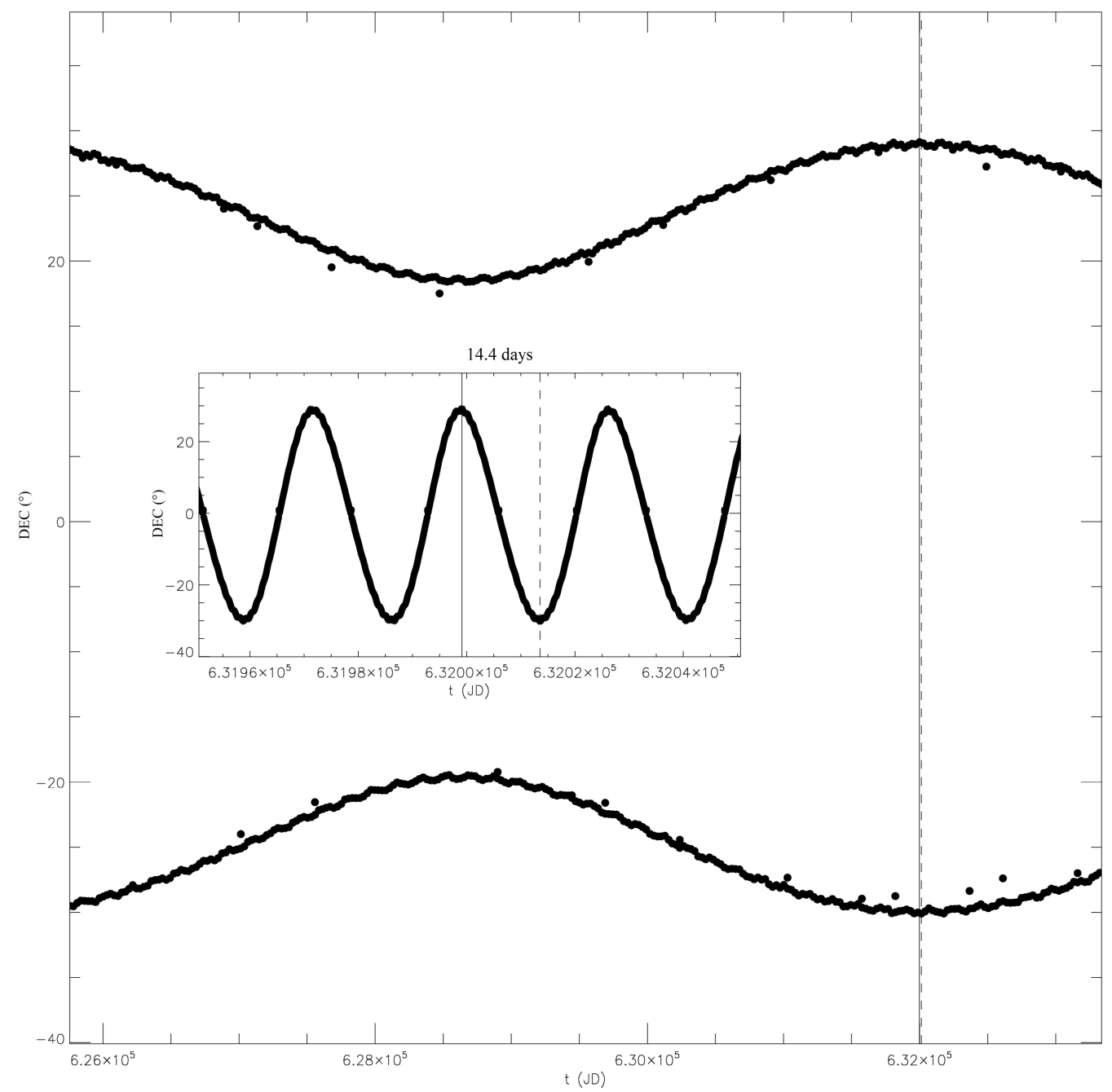

Figure 2. Trend of the lunar declination in function of time between $3000 \mathrm{BC}$ and $2980 \mathrm{BC}$. The declination, on the vertical axis, is expressed in degrees, while the time, on horizontal axis, is in Julian Days (JD). The considered span time is that relative to the first lunar standstill after 3000 BC. The region between the two dotted curves is occupied by a series of very closely-spaced quasi-sinusoidal oscillations that go from the upper to the lower one and vice-versa. For seek of clarity this typical quasi-sinusoidal pattern of the declination has been removed from the main plot (otherwise the region between the two modulating curves would appear completely black), but is shown in the central inset where all the positions of the Moon from 1st March to 30th June 2983 BC are plotted. In this period the absolute maximum (marked by the continuous vertical line) and the absolute minimum (dotted vertical line) of declination are found at a distance of about 14 days each other. Graphics created using IDL. 
of clarity, only the maxima and the minima obtained for the interval between 3000 BC and 2980 BC are illustrated.

It must be said that we have not considered all the minor lunar standstills that occurred from $3000 \mathrm{BC}$ onwards, but we chose to sample only part of the entire dataset available. In particular, the chosen sample was made up of 147 equally spaced minor lunar standstills, starting from the first one in 2983 BC to the last one in $2674 \mathrm{AD}$. This number is large enough to be considered statistically significant. In order to evaluate the secular trend of the available data, we have interpolated them by means of the linear law:

$$
\delta=s t+d
$$

where $\delta$ is the declination of the Moon at its minor standstill, $t$ is the time in Julian Days (JD), while $s=(3.27 \pm$ $0.13) \times 10^{-7} \mathrm{deg} / \mathrm{JD}$ and $d=(-30.37 \pm 0.03) \mathrm{deg}$ are two constants. This law gives a reduced $\chi^{2}$ equal to 0.13 , which, as in the case of the previous section, suggests a good agreement between the data and the hypothesized trend.

Extrapolating the data by means of the linear law (1), the value of $-30.82^{\circ}$ has been thus found for the declination of the Moon on the day of its minor standstill at the epoch of the presumed construction of the enclosure A (8500 BC according to Dietrich, 2011). From this value, it is possible to find the relative rising azimuth. In fact, by applying the well-known formulae of spherical geometry and the model of atmospheric refraction proposed by Karttunen, Kröger, Oja, Poutanen, \& Donner (2007), we have found that the rising azimuth of the Moon in $8500 \mathrm{BC}$ when it found itself at the minor lunar standstill was equal to $130^{\circ}$.

Unlike in the case of enclosure F oriented towards the Sun, it has been found, by means of Google Earth, that there is an absence of reliefs in that direction, at least for a distance of about $350 \mathrm{~km}$.

The agreement between the azimuth measured at Göbekli Tepe for enclosure A, equal to 132 (Collins, 2013), and that obtained by our analysis, equal to $130^{\circ}$, is to be considered quite satisfactory, also considering the large error margin (of the order of some degree) which can be attributed to both the quantities, especially the first one.

It is, then, possible to conclude that the very probable direction towards which the central pillars of enclosure A are pointing is that of the Moon rise on the day in which it was at its minor standstill.

\section{Conclusion}

This work has highlighted various important aspects of certain procedures that should be employed to determine, with the greatest precision possible, the possible alignments towards celestial targets of the enclosures within the Turkish site.

The first point regards the poor reliability of the Thom-Neugebauer empirical rule, which is often employed in the archaeoastronomical field for the evaluation of the rising of a star (Thom, 1967). According to this rule, a star should be visible for the first time when it is at a height on the horizon (in degrees) equal to its visual magnitude. On the contrary, according to Schaefer (1993), we have found that the stars near to the horizon are visible only after they have reached a certain quota above the horizon that does not follow the above rule and that can be estimated only by taking into consideration the effects due to atmospheric extinction. An archaeoastronomical study that neglects the effects of atmospheric extinction can lead to misleading results. That is why, in the analysis that we have carried out, the corrections to make to the measurements of the celestial coordinates, because of all those atmospheric phenomena that limit the visibility of the stars were considered first of all. Other possible causes that could influence the determination of the alignments, like the possible presence of mountains in the directions of the probable orientations of the enclosures, have also been analyzed.

The careful evaluation of the effects caused by atmospheric extinction has enabled us to verify that, as reported by Collins (2013), the central pillars of enclosures D, E, C and B, that characterize the megalithic site of Göbekli Tepe, are in fact turned to face the setting point of Deneb, but these alignments occurred in epochs, as shown in Table 2, that are different from those proposed by Collins (2013). These discrepancies are probably due to the fact that Collins (2013) used an astronomic software, Stellarium, which is not really suitable for the evaluation of the positions of the stars in the past; he also evaluated the effects due to atmospheric extinction adopting an angle of extinction of $2^{\circ}$ fixed a priori. We think, however, that our evaluations are preferable, since they were obtained with the CDC software, which, unlike Stellarium, properly takes into account the effects of the precession of the equinoxes and of the own motion of the stars on the astral coordinates in very remote epochs in the past. In addition, our approach evaluates, in a self-consistent way, all the effects, not only atmos- 
pheric, but also topographical, that limit the visibility of a star near to the horizon.

Another important result of our work consists in having individuated, for the first time, the probable astronomic alignments of two more enclosures at Göbekli Tepe, i.e. enclosures A and F. As far as the F ring is concerned, Collins (2013), reporting a highly qualitative evaluation of the azimuth quantifiable in $67^{\circ}-68^{\circ}$ (or $247^{\circ}$ $248^{\circ}$ ), suggested an alignment of that enclosure towards the rising point of the Sun at the summer solstice or the setting of the Sun at the winter solstice respectively. However, by extrapolating to the date of the presumed construction of enclosure F (around 8500 BC-Dietrich, 2011), the value of the rising azimuth of the Sun on the day of the summer solstice an azimuth of between $59.0^{\circ}$ and $60.4^{\circ}$ was found, that would not be compatible with the orientation of the central pillars as supplied by Collins (2013), of roughly between $67^{\circ}$ and $68^{\circ}$, despite the large margin of error of such a qualitative evaluation. An analogous problem is evidently present for the point of the setting of the Sun at the winter solstice. However, the same extrapolation has enabled us to discover that the above-mentioned orientation coincides within the rising azimuth of the Sun (of between $66.4^{\circ}$ and $67.8^{\circ}$ ) on the day of Harvest Festival, a day approximately halfway between the summer solstice and the autumn equinox.

At first sight, it could appear surprising that a feast strictly linked to agriculture was celebrated in such a distant past, during an epoch when cultivations had to be very rare, if any, in the world. However, according to Salamini, Özkan, Brandolini, Schäfer-Pregl, \& Martin (2002) the first indication of possible domestication of wild cereal by a sedentary, agriculture-based society come from a region called Fertile Crescent where Göbekli Tepe is located and are dated around 10,000 BC, that is a thousand year before the presumed construction of the enclosure F. In fact, also in other places near to Göbekli Tepe, like Cayönü (Turkey), there are examples of organized agricultural activities aimed to grow domesticated cereal (Salamini, Özkan, Brandolini, Schäfer-Pregl, \& Martin, 2002). Moreover there are many evidences that the inhabitants of Göbekli Tepe, apart from hunting, used also the products of the earth as source of sustenance; this is indicated by the mixed sediments derived from agricultural activities found in Layer I of the site (Dietrich, 2011). Therefore, it is possible that Göbekli Tepe's builders celebrated the first harvest of the year in a feast, in which the more recent Harvest Festival could have its roots, by orienting the central pillars of the enclosure F towards the rising point of the Sun in this special day.

As far as enclosure A is concerned, it seems oriented towards one of the stopping points of the Moon, the socalled minor lunar standstill. These points were known to, and studied carefully by ancient civilizations (Thom, 1971; Coffey, 2000). In fact, the azimuth of the rising point of the Moon on the day in which it was at its minor standstill, in the epoch of the presumed construction reported by Dietrich (2011), was found to be equal to $130^{\circ}$. This value, found by extrapolation of the secular trend of the declination of the Moon when it is in this position, is quite in agreement with the one that individuates the orientation of the central pillars of the enclosure, equal to $132^{\circ}$ (Collins, 2013).

In conclusion it is reasonable to think that the builders of Göbekli Tepe, by creating the site, wanted to transmit some of their cosmological beliefs to future generations and that, in particular, they intentionally oriented the central pillars of the enclosures towards some astronomical object. In Table 3 we report a summary of the results, obtained in the present work, which suggest this conclusion.

It must be noted, however, that the data reported in Table 3 cannot be considered definitive, and only constitute good approximations, since, as evidenced by Dietrich (2011), the embryonic state in which the digs lie does

Table 3. Summary of the results obtained in the present work.

\begin{tabular}{ccccc}
\hline Enclosure & Celestial Target & $\begin{array}{c}\text { Astronomical Phenomenon } \\
\text { Associated }\end{array}$ & Azimuth $\left(^{\circ}\right)$ & Ref. Azimuth $\left(^{\circ}\right)$ \\
\hline A & Moon & Minor lunar standstill & 132 & 130 \\
B & Deneb & Cycle of setting/rising & 337 & 337 \\
C & Deneb & Cycle of setting/rising & 345 & 345 \\
D & Deneb & Cycle of setting/rising & 353 & 353 \\
E & Deneb & Cycle of setting/rising & 350 & 350 \\
F & Sun & Harvest Festival & $66-68$ & $67-68$ \\
\hline
\end{tabular}


not allow us to draw definitive conclusions about them. At the same time, because of the uncertainty present in the evaluations of the orientations of the enclosures, estimated to the order of a few degrees, it is not currently necessary to have very close precision of the data extrapolated. That is why it would be opportune, as Magli (2013) also underlines, to carry out investigations in the site by means of geodetic surveys in order to evaluate, with the proper precision, by means of measurements with a theodolite, the orientations that the central pillars of the various enclosures really present, with particular attention paid to that of ring $\mathrm{F}$, which is currently known in a very qualitative way. In addition to this there should be also a study of the surrounding horizon, with the aim of drawing the most realistic possible conclusions (Magli, 2013).

Also, the antiquity of this sacred place is so amazing that it is extremely difficult to propose hypotheses about religion and the rituals that were carried out at the site (Magli, 2013), apart from those already evidenced about the cult of the cycle of birth/death/rebirth of human life that was celebrated by them. In recent years, Archaeoastronomy, when it has been applied with attention, has been quite a valid instrument, showing itself to be reliable for the comprehension of the symbolic world that characterized the ancient cultures (Ruggles, 2005; Magli, 2009). And it is this aspect of archaeoastronomical research that must be exploited to the utmost in future to understand the message that the ancient civilizations wanted to leave to posterity when they built imposing megalithic complexes like Göbekli Tepe all over the planet.

\section{Acknowledgements}

The authors warmly thank two anonymous referees for their suggestions that improved the quality of the original manuscript. The authors are also grateful to Achille Nucita for his technical support in the realization of the scripts used in this work. This research has been supported by the Italian Ministry of University and Research (MIUR).

\section{References}

Belmonte, J. A., Shaltout, M., \& Fekri, M. (2008). On the Orientation of Ancient Egyptian Temples: (4) Epilogue in Serabit el Khadem and Overview. Journal for the History of Astronomy, 39, 1-31.

Calledda, P., \& Proverbio, E. (2004). Analisi statistica degli orientamenti di tombe megalitiche in Sardegna. Rivista Italiana di Archeoastronomia, II, 45-65.

Coffey, J. (2000). Some Moon Rhythms.

http://www.global-vision.org/astroarchaeology/archive/research/papers/sunmoon/index.html

Collins, A. (2013). Göbekli Tepe: Genesis of the Gods. Rochester: Inner Traditions, Bear and Co.

De Lorenzis, A. (2011). Paleoastrometria stellare: Effetti della precessione dell'asse terrestre e dei moti propri. Bachelor's Thesis in Physics, Lecce: University of Salento.

De Lorenzis, A. (2013). Studio archeoastronomico del sito megalitico di Göbekli Tepe (Turchia). Master'sThesis in Physics, Lecce: University of Salento.

Dietrich, O. (2011). Göbekli Tepe. In PPND—The Platform for Neolithic Radiocarbon Dates. http://www.exoriente.org/associated_projects/ppnd_site.php?s=25\#

Hale, R., \& Collins, A. (2013). Göbekli Tepe and the Rebirth of Sirius. http://www.andrewcollins.com/page/articles/Gobekli_Sirius.htm

Horizons User Manual (2013). On-Line Version. http://ssd.jpl.nasa.gov/?horizons_doc

Karttunen, P., Kröger, P., Oja, H., Poutanen, P. M., \& Donner, K. J. (eds.) (2007). Fundamental Astronomy (5th ed.). Berlin: Springer.

Keating, G. (1861). Keating's General History of Ireland. Dublin: J. Duffy.

Magli, G. (2009). Mysteries and Discoveries of Archaeoastronomy: From Giza to Easter Island. New York: Copernicus Books/Springer Science + Business Media: In Association with Praxis Pub.

Magli, G. (2013). Sirius and the Project of the Megalithic Enclosures at Göbekli Tepe. http://arxiv.org/ftp/arxiv/papers/1307/1307.8397.pdf

North, J. (1996). Stonehenge: Neolithic Man and the Cosmos. New York: Harper Collins.

Ruggles, C. L. N. (1985). The Linear Settings of Argyll and Mull. Journal for the History of Astronomy, 16, S105-S132.

Ruggles, C. L. N. (2005). Ancient Astronomy: An Encyclopedia of Cosmologies and Myth. Santa Barbara: ABC-Clio.

Ruggles, C. L. N., \& Burl, H. A. W. (1985). A New Study of the Aberdeenshire Recumbent Stone Circles. 2: Interpretation. 
Journal for the History of Astronomy, 16, S25-S60.

Salamini, F., Özkan, H., Brandolini, A., Schäfer-Pregl, R., \& Martin, W. (2002). Genetics and Geography of Wild Cereal Domestication in the Near East. Nature Reviews Genetics, 3, 429-441.

http://www.molevol.hhu.de/fileadmin/redaktion/Fakultaeten/Mathematisch-Naturwissenschaftliche_Fakultaet/Biologie/Ins titute/Molekulare_Evolution/Dokumente/100.pdf

Schaefer, B. E. (1993). Astronomy and the Limits of Vision. Vistas in Astronomy, 36, 311-361.

Schmidt, K. (2010). Göbekli Tepe-The Stone Age Sanctuaries. New Results of Ongoing Excavations with a Special Focus on Sculptures and High Reliefs. Documenta Praeheistorica, XXXVII, 239-256.

http://arheologija.ff.uni-lj.si/documenta/authors37/37_21.pdf

Schoch, R. (2012). Forgotten Civilization. Rochester, VT: Inner Traditions, Bear and Co.

Taylor, J. R. (1982). An Introduction to Error Analysis. Mill Valley, CA: University Science Books.

Thom, A. (1967). Megalithic Sites in Britain. Oxford: Clarendon Press.

Thom, A. (1971). Preface: Megalithic Lunar Observatories. London: Oxford University Press.

Thom, A. (1974). Astronomical Significance of Prehistoric Monuments in Western Europe. Philosophical Transactions of the Royal Society A, 276, 149-156. http://rsta.royalsocietypublishing.org/content/roypta/276/1257/149.full.pdf

Zedda, M., \& Belmonte, J. (2004). On the Orientations of Sardinian Nuraghes: Some Clues to Their Interpretation. Journal for the History of Astronomy, 35, 85-107. 
Scientific Research Publishing (SCIRP) is one of the largest Open Access journal publishers. It is currently publishing more than 200 open access, online, peer-reviewed journals covering a wide range of academic disciplines. SCIRP serves the worldwide academic communities and contributes to the progress and application of science with its publication.

Other selected journals from SCIRP are listed as below. Submit your manuscript to us via either submit@scirp.org or Online Submission Portal.
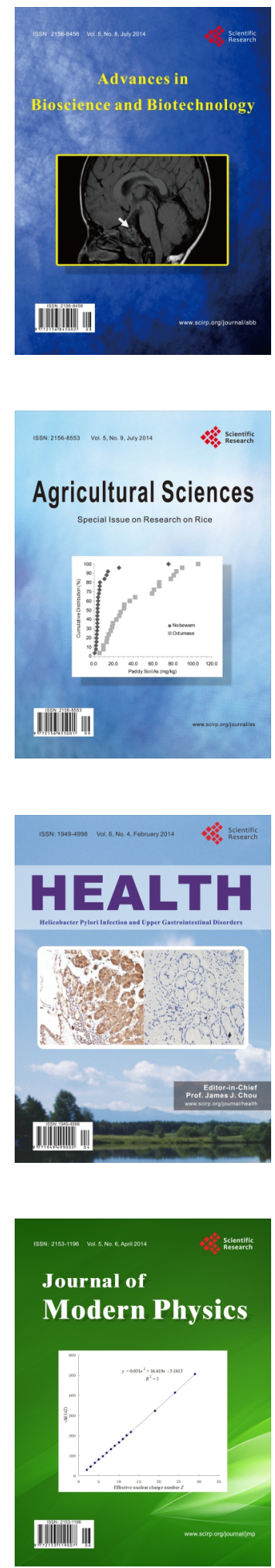
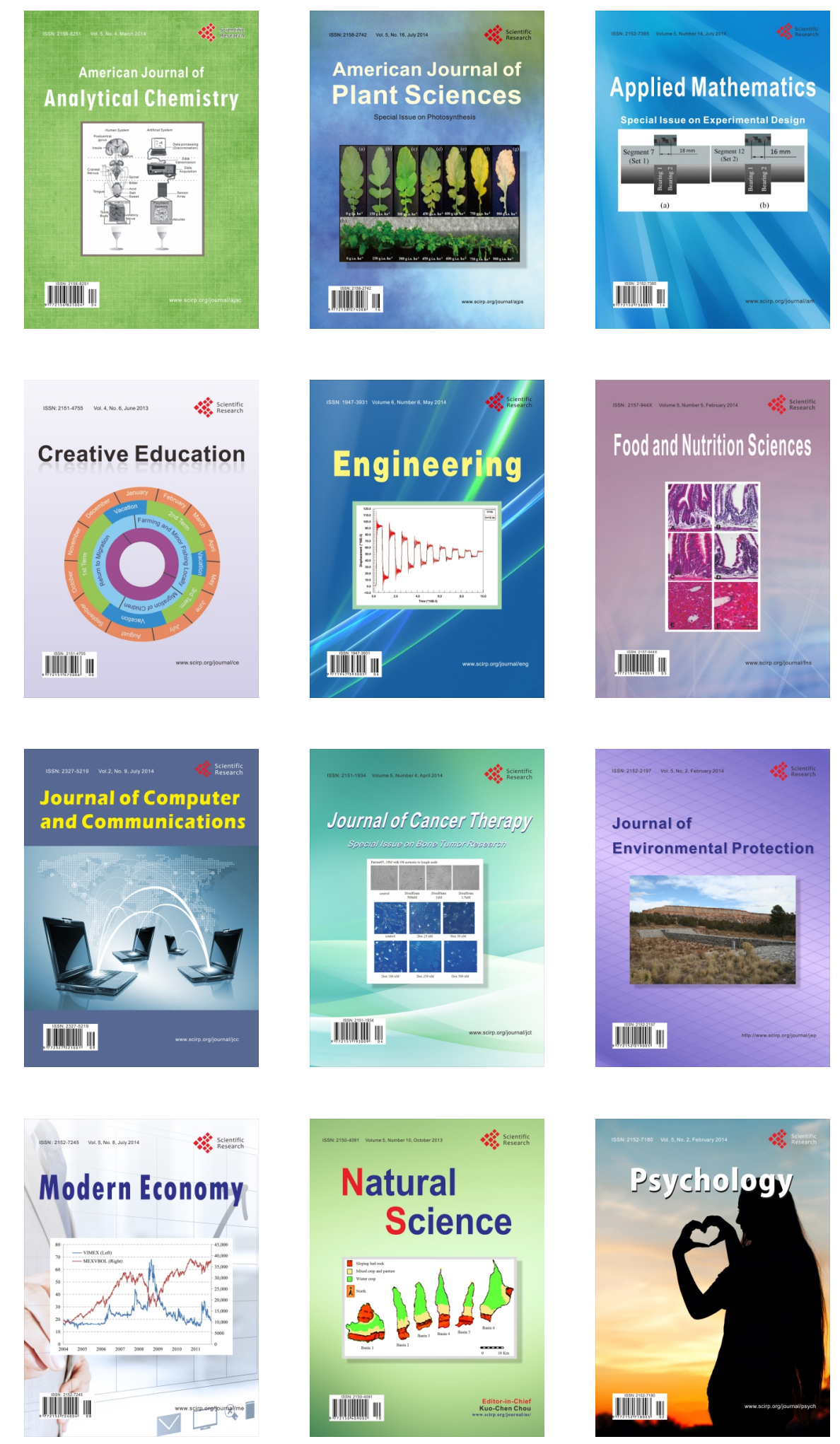